\title{
Pierce and Push: A Simplified Method to Facilitate Laparoscopic Myomectomy
}

\author{
Pei-Ju Wu, MD; Kai-Yun Wu, MD; Chien-Min Han, MD; Hsuan Su, MD; \\ Chin-Jung Wang, MD; Chyi-Long Lee, MD, PhD
}

Background: The aim of this study was to present our experience with a novel approach called the pierce and push (PP) method which uses a stainless steel centimeter probe instead of a $5 \mathrm{~mm}$ claw forceps to enucleate fibroids in a laparoscopic myomectomy (LM).

Methods: A retrospective chart review of 90 women with symptomatic uterine fibroids who underwent an LM was performed. Cases of LM with the PP method were compared with a matched control group of LM with a $5 \mathrm{~mm}$ claw forceps. The operative time, tumor separation time, specimen removal time, amount of blood loss, requirement for blood transfusion and length of hospital stay were compared between groups.

Results: The two groups were matched by age, body mass index, previous cesarean delivery, main fibroid size, and number and weight of fibroids. The tumor separation time was significantly shorter in the PP group than the claw forceps group $(9.7 \pm 3.1$ minutes versus $17.1 \pm 4.4$ minutes, $p<0.001)$. The length of the operation, hospitalization time, specimen removal time, amount of blood loss, and requirement for blood transfusion were not significantly different between groups.

Conclusion: A stainless steel centimeter probe has an advantage over a $5 \mathrm{~mm}$ claw forceps in pushing and pulling fibroids. Our findings indicate that the PP method was much more effective in excision of fibroids than a $5 \mathrm{~mm}$ claw grasper in LM.

(Chang Gung Med J 2012;35:160-6)

Key words: laparoscopy, myomectomy, fibroid, technique, pierce and push

$\mathrm{U}$ terine fibroids occur in at least $20 \%$ of women of reproductive age. Although they are the most common pelvic tumor in women, uterine fibroids are generally asymptomatic. Surgical intervention, including hysterectomy and myomectomy, is currently the best management of symptomatic fibroids. An increasing number of women wish to preserve the uterus regardless of their fertility status,${ }^{(1)}$ and thus myomectomy has become a trend in management.

With the benefits of better cosmetic effects and a faster recovery than the conventional abdominal approach, laparoscopic myomectomy (LM) has become a favorable choice but remains a challenging

From the Division of Gynecologic Endoscopy, Department of Obstetrics and Gynecology, Chang Gung Memorial Hospital at Linkou, Chang Gung University College of Medicine, Taoyuan, Taiwan.

Received: Dec. 14, 2010; Accepted: Oct. 17, 2011

Correspondence to: Dr. Chin-Jung Wang, Department of Obstetrics and Gynecology, Chang Gung Memorial Hospital at Linkou. 5, Fusing St., Gueishan Township, Taoyuan County 333, Taiwan (R.O.C.) Tel: 886-3-3281200 ext. 8258; Fax: 886-3-3288252;

E-mail: wang2260@gmail.com 
technical procedure. ${ }^{(2-6)}$ Three major steps are involved in LM, (1) excision of the fibroid(s), (2) repair of the uterine defect, and (3) extraction of fibroid specimen(s). ${ }^{(6)}$ Because of the limited operative field and instruments, there is more blood loss when dissecting fibroids from the uterine corpus compared with the abdominal approach. The control of operative blood loss is crucial, and thus an effective method of excision is an important strategy.(7)

Few published studies discuss the method of excising fibroid, although LM is now considered a safe and efficient alternative to the open method in well-selected patients. ${ }^{(8-10)}$ The purpose of our study was to describe our experience with a novel approach called the pierce and push (PP) method, which uses a stainless steel centimeter probe instead of a claw forceps and myoma screws to provide easy and effective traction to enucleate fibroids from the surrounding myometrium.

\section{METHODS}

In order to find patients with matching clinical characteristics (age, body mass index and cesarean delivery history) and severity of uterine fibroids (fibroid weight, number of fibroids removed and main fibroid size) for this retrospective case-control study, we reviewed the clinical records of all patients who underwent laparoscopic myomectomy from May 2000 through July 2010 at the Endoscopic Center of Chang Gung Memorial Hospital. All surgeries were performed by one of the authors (CJW). The indications for LM in these patients included menorrhagia, abdominal pain, bulk-related symptoms (urinary frequency, or rectosigmoid compression), and infertility. Before the operation, the patients were informed of the risks and benefits of LM, including the potential need to switch to laparotomy during the operation and the risks of intraoperative bleeding, transfusion, and adhesions. Written informed consent was obtained from all subjects.

Twenty-five patients had menometrorrhagia and underwent diagnostic hysteroscopy to exclude pathologic lesions in the uterine cavity. Gonadotropin releasing-hormone agnoists were not administered preoperatively. All women had bowel preparation the morning of surgery. Intravenous cephalosporin prophylaxis was given just before surgery.

The procedure was conducted with the patient in the dorsolithotomy Trendelenburg position with both legs protected by elastic bandages; a Foley catheter was inserted for continuous urinary drainage. A uterine manipulator was placed into the uterus (for women with prior sexual activity). A videolaparoscopy was performed with a 5-mm principal trocar introduced through the umbilicus. Three ancillary 5-mm cannulas were placed under laparoscopic visualization, two in the left lower quadrant lateral to inferior epigastric arteries, and the other in the right lower quadrant. For the patients with a uterine size greater than 14 weeks' gestation, a $0.5 \mathrm{~cm}$ vertical skin incision was made with a number 11 blade at the midpoint between the umbilicus and xyphoid process where a $5 \mathrm{~mm}$ cannula was inserted. ${ }^{(11)}$ Two puncture sites, both $5 \mathrm{~mm}$ were made bilaterally in the lower abdomen at the paramedian line at the level of the umbilicus. The other cannula was introduced at the paramedian line, just above the pubic hairline. Once cannula placement was complete, adhesions were lysed as necessary.

After identifying the location of all fibroids, a transverse incision was made on the serosa overlying the largest tumor using a conventional unipolar electrode. The incision was extended into the pseudocapsule down to the characteristically pearly white material constituting the tumor. Additional fibroids located in the same area were removed through the same incision. However, a new incision was necessary for nonadjacent fibroids. For group A (pierce and push method), a stainless steel centimeter probe was then inserted into the fibroid to apply traction (Fig. 1) while a unipolar scissors was used to sharply dissect the fibroid in the cleavage plane to leverage the tumor against the uterine wall and pry it out of its bed (Fig. 2). A bipolar electrode was used to desiccate fibroid feeding vessels located between the pseudocapsule and myometrium. In group B, the control group, a 5-mm claw grasper was used to apply traction on the mass, and the remaining procedures were similar to group A. The 5-mm claw grasper was not standard equipment for a laparoscopy. Therefore the decision to choose the PP method or the claw grasper was dependent on the facilities of the operating theater.

The uterine surgical defect was closed by onelayer suturing. Excessive myometrium and serosa were trimmed off. 0 monofilament poliglecaprone 25 (Monocryl, Ethicon Inc, Somerville, NJ, U.S.A.) on 
a large curved needle was used to make a deep, wide $(1 \mathrm{~cm}$ from the cut edge of the incision) bite. After the needle entered the uterus through the serosa to the myoma bed and emerged at the superficial level in a $U$ shape, it was then grasped and reapplied in a reverse fashion. Intracorporeal knot tying was then done. A continuous non-running-lock suture at $1-\mathrm{cm}$ increments was then carried out, with each suture penetrating the full thickness of the myometrium, following a method similar to that applied during laparotomy.

Specimens were removed through a posterior

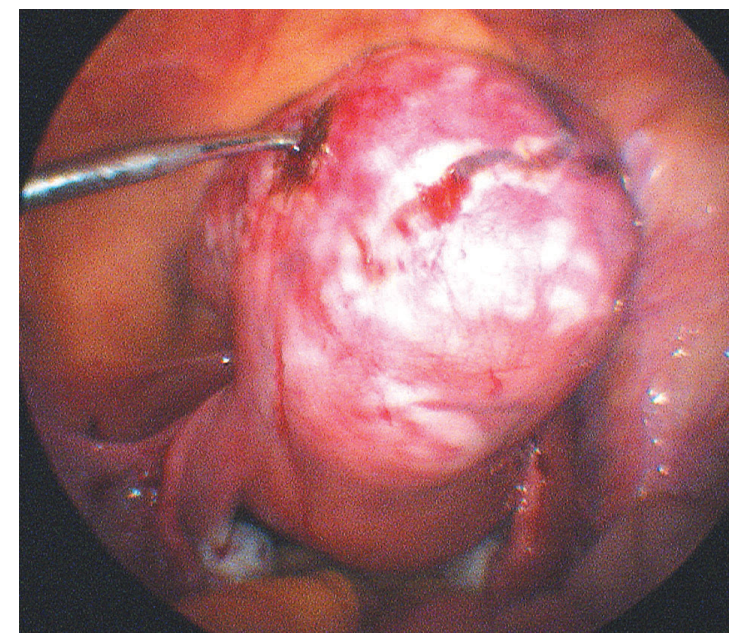

Fig. 1 A centimeter probe is inserted into the fibroid to apply traction.

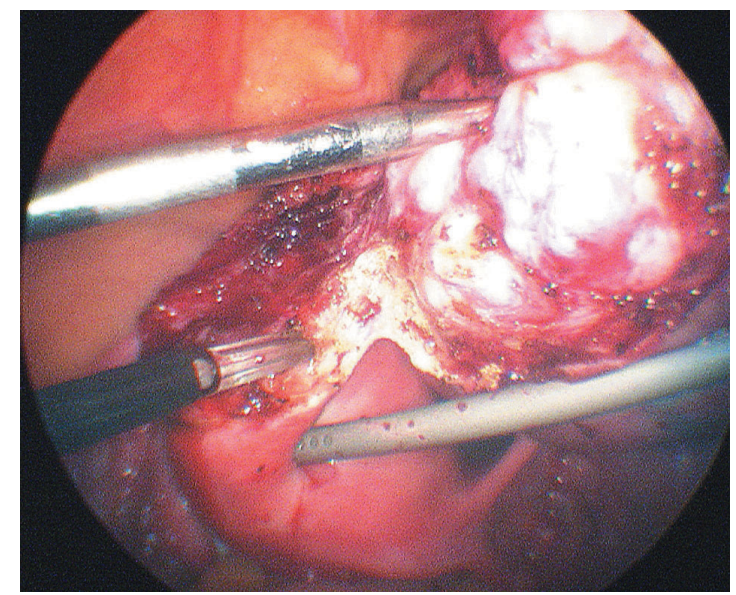

Fig. 2 A unipolar scissors is used to sharply dissect the fibroid in the cleavage plane to leverage the fibroid against the uterine wall and pry it out of its bed. colpotomy. Medium and large fibroids were first morcellated with a scalpel or scissors. After removal of all fibroids, the colpotomy incision was closed with 2-O polyglycolic acid suture. Pneumoperitoneum was reestablished at this time, and the peritoneal cavity was irrigated and lavaged until fluid ran clear. A Jackson-Pratt drain was introduced through a 5-mm access site if complete hemostasis could not be achieved. If the specimen had to be removed from the abdominal wall, a 12-mm electromechanical morcellator (Storz, Tuttlingen, Germany) was used to ease extraction of the specimen. All port sites were sutured with 3-0 polyglycolic acid suture at the level of the fascia to prevent herniation. The skin was approximated by sterile adhesive tape.

\section{Statistics}

A retrospective chart review of all patients who had LM with the PP method was performed. All cases were compared by age, body mass index, number of cesarean deliveries, and number, location, and size of removed fibroids with a matched control group of patients who had LM with a claw grasper, which had been performed by the same surgeon. Continuous variables were compared with the paired $\mathrm{T}$ test and categorical values with the McNemar test. All probability values were two-sided. Significance was accepted at a probability below 5\%. SPSS for Windows version 13.0 (SPSS Inc., Chicago, IL, U.S.A.) was used for the statistical calculations.

\section{RESULTS}

Of 721 women who underwent LM during the study period, 5 had procedures assisted by a minilaparotomy, and 49 assisted by a vaginal approach. Of the 667 remaining patients who underwent pure LM, 425 were performed with the PP method and the rest with a claw grasper. After matching the clinical characteristics and severity of uterine fibroids, 45 women in each group were enrolled respectively. All 90 laparoscopic procedures were performed uneventfully without any conversion to laparotomy. Both groups of patients were similar in terms of age, body mass index, and histories of cesarean section deliveries. The indications for LM in these patients are listed in Table 1. Five patients in group A (PP method) and 6 in the group B (claw grasper) underwent concomitant adnexal surgery, and 2 patients in the group 
A and 3 patients in the group B underwent hysteroscopic removal of endometrial polyps. Otherwise, no additional procedures were performed.

The outcomes of the two groups are summarized in Tables 2 and 3. The mean operating time, total weight of the fibroids, number of fibroids removed, size of the main fibroid, postoperative stay, specimen removal time, and requirement for blood transfusion were similar in both groups. The mean

Table 1. Surgical Indications for Patients Undergoing Laparoscopic Myomectomy with the Pierce-and-push (PP) Method and with Claw Forceps

\begin{tabular}{lcc}
\hline Indication & $\begin{array}{c}\text { PP group } \\
(\mathrm{n}=45)\end{array}$ & $\begin{array}{c}\text { Claw forceps group } \\
(\mathrm{n}=45)\end{array}$ \\
\hline Menorrhagia & 16 & 15 \\
Abdominal pain & 5 & 4 \\
Bulk-related symptoms & 35 & 33 \\
Infertility & 3 & 4 \\
\hline
\end{tabular}

tumor separation time was significantly shorter in the PP group. One patient in the PP group had intraoperative blood loss $>500 \mathrm{ml}$. The extreme blood loss was mainly caused by removal of a large intramural tumor $(13 \mathrm{~cm})$. No major complications, such as ureter, bladder, or bowel injury, occurred in any of the cases. Four patients in the PP group and 2 in the claw grasper group required blood transfusions with packed red blood cells (2-4 units) because of heavy blood loss $(>300 \mathrm{~mL})$. Two specimens each in the $\mathrm{PP}$ group and claw grasper group were removed via posterior colpotomy.

Histologic examination of the resected tissue showed leiomyomatous tissue in all patients. Four specimens had hyaline degeneration and one had calcified degeneration. Three specimens were cellular leiomyomas. Eight patients had adenomyosis concomitantly. No sarcomatous change was observed. Three women had uterine cavity broken during the operation and a control hysteroscopy performed 4 weeks postoperatively showed no intrauterine adhesions.

Table 2. Comparison of Fibroids Removed in Patients Undergoing Laparoscopic Myomectomy with the Pierce-and-push (PP) Method and with Claw Forceps

\begin{tabular}{lccc}
\hline & PP group $(\mathrm{n}=45)$ & Claw forceps group $(\mathrm{n}=45)$ & $p$ \\
\hline Fibroid weight $(\mathrm{g})$ & $207.9 \pm 186.8(70-850)$ & $174.6 \pm 203.3(60-862)$ & 0.449 \\
Fibroids removed (no.) & $2.5 \pm 1.8(1-6)$ & $2.2 \pm 1.7(1-8)$ & 0.366 \\
Main fibroid size (cm) & $8.2 \pm 1.8(6-15)$ & $7.5 \pm 2.6(5-15)$ & 0.148 \\
\hline
\end{tabular}

Values are mean \pm S.D. (range).

Table 3. Comparison of Outcome Variables in Patients Undergoing Laparoscopic Myomectomy with the Pierce-and-push (PP) Method and with Claw Forceps

\begin{tabular}{lcrc}
\hline & PP group $(\mathrm{n}=45)$ & Claw forceps group $(\mathrm{n}=45)$ & $p$ \\
\hline Operating time (min) & $91.6 \pm 26.0(45-150)$ & $100.2 \pm 35.3(40-200)$ & 0.150 \\
Tumor separation time (min) & $9.7 \pm 3.1(6-20)$ & $17.1 \pm 4.4(10-30)$ & $<.001$ \\
Specimen removal time (min) ${ }^{\dagger}$ & $16.1 \pm 14.7(5-75)$ & $12.9 \pm 12.3(3-60)$ & 0.237 \\
Blood loss (ml) & $159.6 \pm 136.5(10-550)$ & $142.7 \pm 113.4(10-400)$ & 0.521 \\
Postoperative stay (days) & $2.4 \pm 0.6(2-4)$ & $2.5 \pm 0.6(2-4)$ & 0.160 \\
Blood transfusion, no. $(\%)$ & $4(8.9)$ & $2(4.4)$ & $0.289 *$ \\
\hline
\end{tabular}

Values are mean \pm S.D. (range) or $\mathrm{n}(\%)$; *: McNemar test; $\uparrow$ : Time from performing the colpotomy to closure of the colpotomy or from introducing a morcellator to complete removal of specimens. 


\section{DISCUSSION}

Since the first introduction of LM by Semm in $1979{ }^{(12)}$ many reports of this technique have been published worldwide. Although improvements in laparoscopic techniques and instruments during the last 3 decades have helped gynecologists overcome several limitation in LM, this technique remains a challenging technical procedure, especially in controlling operative blood loss.

Excision of the fibroid(s) is the first step of LM. Because of the limited operative field and instruments, there is more blood loss when dissecting fibroids from the uterine wall compared with the abdominal approach. Different instruments have been introduced to overcome this problem, such as the claw grasper and myoma screws. The grasping forceps provides a sharp bite and fixation of fibroids, but there is a risk of injury of internal organs such as the bowel..$^{(13,14)}$ Myoma screws facilitate deeper stabilization of fibroids but it has been reported that they are easily broken and are a possible risk to the patient. $^{(8-10)}$

There are at least four types of threads in commercially available myoma screws, the standard wood screw, short-pitch corkscrew, long-pitch corkscrew, and special buttress-thread screw. ${ }^{(8)}$ According to Tintara et al, the long-pitch corkscrew has the lowest traction force with a very low bending strength compared with other screw thread forms. They concluded that the long-pitch corkscrew should not be used for laparoscopic fibroid extraction. ${ }^{(8)}$

In our experience, a centimeter probe which is made of stainless steel, could assist in LM by punching and pushing into the fibroid to apply fixation and traction while another instrument is used to bluntly dissect the fibroid in the cleavage plane to leverage the tumor against the uterine wall and pry it out of its bed. The blunt end of the centimeter probe prevents injury to the internal organs. It is made without separate parts which further avoids the problem of breakage during manipulation. Through this PP method, fibroids can be excised in a more safe and effective manner. Nevertheless, the PP method might be limited in managing fibroids with degeneration or relatively small ones where optimal fixation of a probe is difficult.

In this study, all laparoscopic procedures were performed uneventfully without conversion to laparotomy. Although the PP group had a significantly shorter tumor separation time, the total operating times were similar in both groups. This might be because the weight and number of fibroids removed, and the main fibroid size were somewhat greater in the PP group, although there were no statistical significance. Putting all these factors into consideration, the pierce and push method showed clinical feasibility and effectiveness.

In conclusion, more women with symptomatic uterine fibroids request laparoscopic management instead of a hysterectomy. As the effective removal of fibroid(s) is the decisive step in LM, using the proper instrument to perform traction-countertraction during manipulation is very important. The conventional claw grasper has drawbacks in that the traction force is not sufficient and it slips easily during pushing and pulling. A centimeter probe can easily pierce a fibroid, facilitating the enucleation procedure, resulting in less operative blood loss and shorter operating times. In this study we successfully demonstrated the PP method was much more effective in excision of fibroids than the conventional claw grasper. However a retrospective case control study can result in statistical biases. A larger prospective study is needed to investigate the feasibility and effectiveness of this maneuver.

\section{REFERENCES}

1. Altgassen C, Kuss S, Berger U, Loning M, Diedrich K, Schneider A. Complications in laparoscopic myomectomy. Surg Endosc 2006;20:614-8.

2. Nezhat F, Seidman DS, Nezhat C, Nezhat CH. Laparoscopic myomectomy today. Why, when and for whom? Hum Reprod 1996;11:933-4.

3. Dubuisso JB, Fauconnier A, Babaki-Fard K, Chapron C. Laparoscopic myomectomy: a current view. Hum Reprod Update 2000;6:588-94.

4. Landi S, Zaccoletti R, Ferrari L, Minelli L. Laparoscopic myomectomy: technique, complications, and ultrasound scan evaluations. J Am Assoc Gynecol Laparosc 2001;8: 231-40.

5. Hurst BS, Matthews ML, Marshburn PB. Laparoscopic myomectomy for symptomatic uterine myomas. Fertil Steril 2005;83:1-23.

6. Wang CJ, Yuen LT, Lee CL, Kay N, Soong YK. Laparoscopic myomectomy for large uterine fibroids. A comparative study. Surg Endosc 2006;20:1427-30. 
7. Wang CJ, Yuen LT, Han CM, Kay N, Lee CL, Soong YK. A transient blocking uterine perfusion procedure to decrease operative blood loss in laparoscopic myomectomy. Chang Gung Med J 2008;31:463-8.

8. Tintara H, Aiyarak P, Mitarnun W, Geater A. Assessment of the physical properties of laparoscopic myoma-fixation devices. Surg Endosc 2005;19:240-4.

9. Tintara H, Aiyarak P, Mitarnun W, Geater A. Effect of thread pitch on pull-out strength of laparoscopic myoma screws. J Obstet Gynaecol Res 2006;32:428-33.

10. Yoon HJ, Kyung MS, Jung US, Choi JS. Laparoscopic myomectomy for large myomas. J Korean Med Sci 2007;22:706-12.
11. Lee CL, Huang KG, Jain S, Wang CJ, Yen CF, Soong YK. A new portal for gynecologic laparoscopy. J Am Assoc Gynecol Laparosc 2001;8:147-50.

12. Semm K. New methods of pelviscopy (gynecologic laparoscopy) for myomectomy, ovariectomy, tubectomy and adnectomy. Endoscopy 1979;11:85-93.

13. El-Banna M, Abdel-Atty M, El-Meteini M, Aly S. Management of laparoscopic-related bowel injuries. Surg Endosc 2000;14:779-82.

14. van der Voort M, Heijnsdijk EA, Gouma DJ. Bowel injury as a complication of laparoscopy. Br J Surg 2004;91: 1253-8. 


\title{
刺入及推動：一個幫助操作腹腔鏡子宮肌瘤切除術的簡化方法
}

\author{
吴珮如 吴凱筠 韓健明 蘇軒 王錦榮 李奇龍
}

背景：本篇文章之目的乃在發表以不銹鋼材質的穿刺棒代替 5 毫米有爪鉗, 利用刺入及推 動法於腹腔鏡子宫肌瘤切除術中摘除子宫肌瘤的手術經驗。

方 法: 回溯性病歷分析 90 名具有臨床症狀之子宫肌瘤患者, 在接受腹腔鏡子宫肌瘤切除手 術時, 分成不銹鋼穿刺棒的刺入及推動法和 5 毫米有爪鉗雨組, 分別比較雨組之手 術時間、肌瘤從子宫分離時間, 檢體取出時間、手術失血量、輸血個案數及住院天 數。

結 果: 雨組病人在年龄、身體質量指數、剖腹產次數、子宫肌瘤的大小、數目及重量皆互 相吻合。以不銹鋼穿刺棒的刺入及推動法這組的肌瘤從子宫分離時間 $(9.7 \pm 3.1$ 分 鐘) 明顯短於 5 毫米有爪鉗組 $(17.1 \pm 4.4$ 分鐘 $)(p<0.001)$ 。兩組在手術時間、住院 天數、檢體取出時間、手術失血量、輸血個案數之比較則無臨床差異。

結 論: 在摘除子宫肌瘤手術時, 推拉子宫肌瘤的效果, 不銹鋼穿刺棒的刺入及推動法優於 5 毫米有爪鉗, 本研究顯示刺入及推動法, 在腹腔鏡子宫肌瘤切除術中比使用 5 毫米 有爪鉗能更有效地箔助肌瘤切除。

(長庚醫誌 2012;35:160-6)

關鍵詞：腹腔鏡手術, 子宫肌瘤切除手術, 子宫肌瘤, 技術, 刺入及推動 